\title{
Method for Determining the Concentration of Unknown Combustible Gas ${ }^{\dagger}$
}

\author{
Alexey Karelin 1,* , Evgeny Karpov ${ }^{1}$, Alexander Baranov ${ }^{1}$, Sergey Mironov ${ }^{2}$ and Elena Karpova ${ }^{3}$ \\ 1 LLC “Smartsens”, 140004 Lyubertsy, Moscow Region, Russia; karpovef@yandex.ru (E.K.); \\ baranov_64@mail.ru (A.B.) \\ 2 LLC “NTC IGD”, 140004 Lyubertsy, Moscow Region, Russia \\ 3 "STANKIN" - Moscow State Technological University, 105005 Moscow, Russia \\ * Correspondence: proger007@gmail.com; Tel.: +7-985-978-5100 \\ † Presented at the Eurosensors 2017 Conference, Paris, France, 3-6 September 2017.
}

Published: 9 August 2017

\begin{abstract}
It is known that catalytic sensors have different sensitivities to different combustible gases. Usually gas analyzers are calibrated by methane and not suitable for measuring other flammable gases. Correction is needed to get real concentration of other gases. In this paper it is shown that sensor sensitivity to one particular gas alters with sensor temperature and each gas has its own rate of reducing the sensitivity with a further increase of temperature. It allows us to calculate the concentration of unknown flammable gas. Applying this method decreases measurement error from $30-40 \%$ to $5-10 \%$ for hydrocarbons.
\end{abstract}

Keywords: explosions; gas detectors; gas measurement; hydrocarbon detection

\section{Introduction}

Industrial processes of mining and quarrying, transporting and processing of minerals in different industry branches are connected with real risk of generating explosive atmosphere in technological areas, warehouses and open spaces. Periodically occurring natural gas explosions show the real danger of such risks. Accidents are severe, lead to casualties and huge material damage.

Catalytic sensors along with semiconductor sensors are ones of the most widespread sensors to implement combustible gas control [1,2]. The advantages of catalytic sensors are in low cost, selectivity only to flammable gases and vapors. However, there are some drawbacks, one of which is the unequal sensitivity to different flammable gases.

The most important issue in measuring different combustible gases is the fact that every gas has its own Lower Explosive Limit (LEL). Usually instruments are calibrated to measure methane as the most widespread flammable gas. To obtain concentration of other gases special tables allowing recounting results from methane concentration to concentration of another known gas are used. But it is not useful and besides that the exact composition is rarely known. There were a lot of attempts to bring measurement results to a common denominator [3].

This paper describes one of possible variants to converge sensitivities for catalytic sensors for most widely spread and most used gases.

\section{Materials and Methods}

As methane catalytic sensors produced by "NTC IGD" Ltd. were chosen (Figure 1a). Sensors represent a platinum coil of cast micro wire with quartz insulation. A core diameter is $10 \mu \mathrm{m}$ and insulation thickness is $2 \mu \mathrm{m}$. A principle of operation of such sensors based on flameless burning (oxidation) of combustible gas on the catalytic active surface and measuring the amount of released heat, which is proportional to the concentration of combustible gas [4]. 


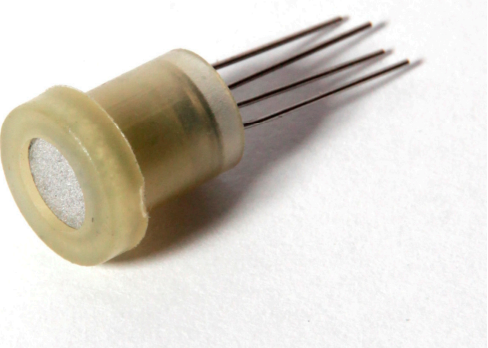

(a)

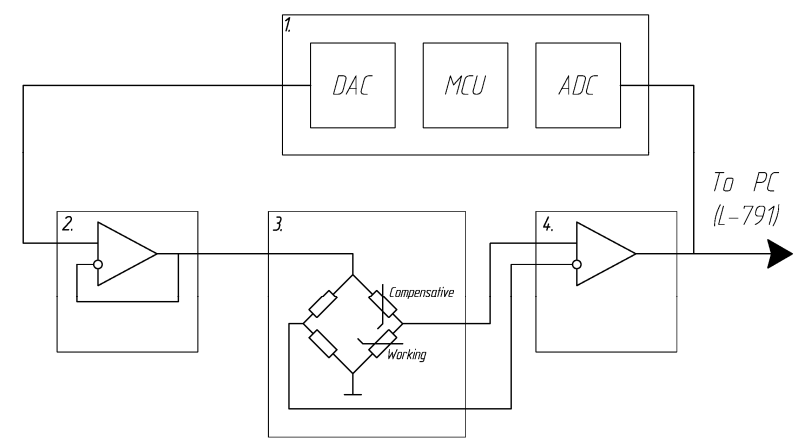

(b)

Figure 1. (a) - photo of the sensor, (b) - scheme of test stand.

Figure $1 \mathrm{~b}$ shows the scheme of test stand. The scheme consists of (1) AduC831 microcontroller with two 12-bit DAC (Digital-to-Analog Convertor) and 8-channel 12-bit ADC (Analog-to-Digital Convertor). DAC is used to set sensor supply voltage. Power supply for sensor is based on (2) an operational amplifier working as a voltage follower. (3) In measuring part, working and compensative sensitive elements are installed in a Wheatstone bridge. (4) Amplifying part is built on the AD8532 working as a differential amplifier. As a data acquisition system there used universal input/output PCI-board L-791 produced by L-card. It has 32 analog input channels with 14-bit ADCs and the sample-rate $400 \mathrm{kHz}$.

The number of different gas mixtures with air with pre-explosive concentration of flammable gases was used for the experiment. Detailed description of mixtures is presented in Table 1.

Table 1. Calibration gas mixtures with air used.

\begin{tabular}{cccc}
\hline Gas & Concentration, $\%$ v/v & LEL, \% v/v & Concentration, \% LEL \\
\hline $\mathrm{CH}_{4}$ & $1.01 \%$ & $4.4 \%$ & $23 \%$ \\
$\mathrm{C}_{3} \mathrm{H}_{8}$ & $1.01 \%$ & $1.7 \%$ & $59 \%$ \\
$\mathrm{C}_{4} \mathrm{H}_{10}$ & $0.665 \%$ & $1.8 \%$ & $37 \%$ \\
$\mathrm{C}_{6} \mathrm{H}_{14}$ & $0.485 \%$ & $1.24 \%$ & $39 \%$ \\
$\mathrm{H}_{2}$ & $0.96 \%$ & $4 \%$ & $24 \%$ \\
\hline
\end{tabular}

To get sensor response at different temperatures the following method was chosen. After pouring the chamber with the calibration gas mixture the stand was turned on. Bridge supply voltage was varied from $400 \mathrm{mV}$ (200 mV for working element) to $3100 \mathrm{mV}$ (1550 for working element) in increments of $50 \mathrm{mV}$. Between measures there was a $10 \mathrm{~s}$ pause to complete transients. The output was recorded for $5 \mathrm{~s}$ after the pause and after that average value was written into memory.

\section{Results and Discussion}

While measuring in regular Wheatstone bridge, an error may exceed $100 \%$ measuring hydrogen relative to methane. It was noted that heavier gases, having less diffusion coefficient and higher heat-generation ability, have low output signal (compared to methane). While measuring such gases with devices calibrated to methane it is necessary to correct measurement results. In other words, the smaller diffusion coefficient, the bigger correction coefficient must be applied to align measurement results.

Figure 2 presents averaged response of the sensors. At the beginning, when temperature is not sufficient for catalytic reactions, sensitivity of the sensor is zero. Then, after reaching the initial temperature of oxidation reaction, the sensitivity increases with sensor temperature. Oxidation in this zone has kinetic character, as a result the sensitivity is non-linear, i.e., it depends on concentration of the analyzed gas. With increasing temperature, the oxidation becomes diffusive, that is all amount of gas able to reach the surface of catalyst is oxidized. In a diffusion zone a section, where sensitivity does not depend on temperature change, is selected. It is the working temperature of sensing element. 
Further increase of temperature causes fall of sensitivity associated with both the increase of heat transfer (e.g., by radiation) and the properties of particular reaction, the specific properties of the oxidizing gas (e.g., desorption energy of the fuel component from the surface of the active site of the catalyst).

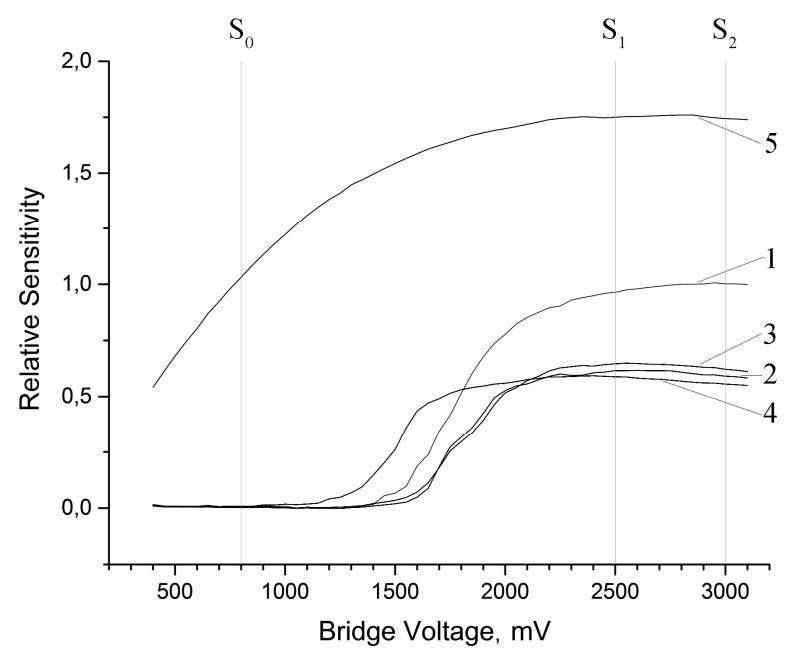

Figure 2. Sensor response under various sensor temperatures. 1 -methane, 2 -propane, 3-butane, 4-hexane, 5-hydrogen.

Figure 2 also shows that each gas has its own onset oxidation temperature, temperatures of the diffusive oxidation zone and rate of reducing the sensitivity with a further increase of temperature. The kinetic zone of burning is characterized by instability of ongoing process of oxidation, and thus it is excluded from the analysis zone. Consequently the most interesting section is the diffusion zone of flameless oxidation, whereas the individuality of different gases burning, that is differences in burning conditions, is better seen in the subsequent area of reducing the element sensitivity.

Based on the above provisions, the followed measurement algorithm is proposed that allow reducing the discrepancy of measurement results.

1 A sensor works in pulse mode. The sensor must be turned off when measurements start. All measuring signals $S=\left(U_{R}-U_{0}\right)$ are calculated as difference between measured voltages with gas presented in chamber $\left(U_{R}\right)$ and voltages measured under the same conditions in clean air $\left(U_{0}\right)$. A voltage pulse $U_{P}=800 \mathrm{mV}$ is supplied on the sensitivity element, corresponding to a temperature $100-110{ }^{\circ} \mathrm{C}$, and maintained for $500 \mathrm{~ms}$. At the end of the pulse an output signal $S_{0}$ is measured-this signal is a reference (comparative) one.

2 A voltage pulse corresponding to a working voltage of a sensitive element for methane is supplied, $430-450{ }^{\circ} \mathrm{C}, 2.5 \mathrm{~V}$, and maintained for $500 \mathrm{~ms}$. After that an output signal $S_{1}$ is measured, and a methane signal as $S_{M}=S_{1}-S_{0}$ is calculated.

3 A voltage pulse $470-490{ }^{\circ} \mathrm{C}, 3.0 \mathrm{~V}$ is supplied for $200 \mathrm{~ms}$, a correction output signal $S_{2}$ is measured. A correction factor $K=S_{1} / S_{2}$, characterizing the rate of sensitivity decrease on the analyzed gas during the temperature increase, is calculated.

4 Corrected signal is calculated using empiric formula:

$$
S_{R}=S_{M} \times \exp (F \times K) / C_{S}
$$

where $F$-the coefficient characterizing the rate of sensitivity decrease for a particular sensor, $C_{S}$ - the correction coefficient to align results of measurement. $F, C_{S}$ calculates during sensor calibration by exposing them to calibration gas mixtures with air and must be included in MCU or other data processing means.

It is important to note that sensors have very high sensitivity to hydrogen because of high diffusion coefficient. At the same time hydrogen has very low ignition temperature, so reference $S_{0}$, taken at the temperature $100-110{ }^{\circ} \mathrm{C}$, does not equal 0 , comparing to other gases. As a result of 
subtracting $S_{0}$ the sensitivity to hydrogen essentially approaches to sensitivity to other gases, and the correction gives satisfactory result. Table 2 presents the results of the corrected measurements.

Table 2. The measurement results for unknown flammable gas with concentration 25\% LEL.

\begin{tabular}{ccccccccc}
\hline Gas & Sensor \# & $S_{0,} \mathbf{m V}$ & $S_{1}, \mathbf{m V}$ & $S_{2,} \mathbf{m V}$ & $C_{\text {def, }} \% \mathbf{L E L}$ & $C_{f l,} \% \mathbf{L E L}$ & $\Delta$ def & $\Delta R$ \\
\hline \multirow{3}{*}{$\mathrm{H}_{2}$} & 1 & 46.26 & 81.80 & 83.38 & 49.25 & 26.15 & $97.0 \%$ & $4.6 \%$ \\
& 2 & 39.68 & 77.34 & 78.64 & 39.31 & 23.62 & $57.3 \%$ & $-5.5 \%$ \\
& 3 & 42.52 & 71.40 & 68.43 & 47.55 & 23.05 & $90.2 \%$ & $-7.8 \%$ \\
\hline \multirow{3}{*}{$\mathrm{CH}_{4}$} & 1 & 0.00 & 41.52 & 45.03 & 25.00 & 25.00 & - & - \\
& 2 & 0.00 & 49.18 & 51.63 & 25.00 & 25.00 & - & - \\
& 3 & 0.00 & 37.54 & 37.15 & 25.00 & 25.00 & - & - \\
\hline \multirow{3}{*}{$\mathrm{C}_{3} \mathrm{H}_{8}$} & 1 & 0.00 & 28.15 & 27.10 & 16.94 & 25.20 & $-32.2 \%$ & $0.8 \%$ \\
& 2 & 0.00 & 28.95 & 28.45 & 14.72 & 22.90 & $-41.1 \%$ & $-8.4 \%$ \\
& 3 & 0.00 & 24.19 & 22.62 & 16.11 & 22.27 & $-35.6 \%$ & $-10.9 \%$ \\
\hline \multirow{3}{*}{$\mathrm{C}_{4} \mathrm{H}_{10}$} & 1 & 0.00 & 30.09 & 29.88 & 18.12 & 24.19 & $-27.5 \%$ & $-3.3 \%$ \\
& 2 & 0.00 & 30.59 & 29.82 & 15.56 & 25.59 & $-37.8 \%$ & $2.4 \%$ \\
& 3 & 0.00 & 24.96 & 22.87 & 16.62 & 25.94 & $-33.5 \%$ & $3.7 \%$ \\
\hline \multirow{3}{*}{$\mathrm{C}_{6} \mathrm{H}_{14}$} & 1 & 0.00 & 29.21 & 28.86 & 17.59 & 23.89 & $-29.6 \%$ & $-4.4 \%$ \\
& 2 & 0.00 & 26.98 & 25.60 & 13.71 & 27.32 & $-45.1 \%$ & $9.3 \%$ \\
& 3 & 0.00 & 21.85 & 19.43 & 14.55 & 27.25 & $-41.8 \%$ & $9.0 \%$ \\
\hline
\end{tabular}

$C_{\text {def }}$-default measured concentration, $C_{f l}$-corrected concentration. $\Delta_{\text {def-measurement error }}$ for source results, $\Delta R-$ measurement error for corrected results.

\section{Conclusions}

In the article a method of correction of measurement results on catalytic sensors working with various flammable gases using correction factor $\mathrm{K}$ characterizing the rate of sensitivity decrease during the temperature increase was described.

Suggested measurement algorithm allows aligning of measurement results for different combustible gases. Measurement error decreases from $90 \%$ to less than $10 \%$ while measuring hydrogen. For hydrocarbons the error decreases from $30-40 \%$ to $0-10 \%$.

Conflicts of Interest: The authors declare no conflict of interest.

\section{References}

1. Somov, A.; Baranov, A.; Suchkov A.; Karelin, A.; Mironov, S.; Karpova, E. Improving interoperability of catalytic sensors. Sens. Actuators B Chem. 2015, 221, 1156-1161, doi:10.1016/j.snb.2015.07.082.

2. Vasiliev, A.A.; Lipilin, A.S.; Mozalev, A.M.; Lagutin, A.S.; Pisliakov, A.V.; Zaretskiy, N.P.; Samotaev, N.N.; Sokolov, A.V. Gas sensors based on MEMS structures made of ceramic $\mathrm{ZrO}_{2} / \mathrm{Y}_{2} \mathrm{O}_{3}$ material. Proc. SPIE Int. Soc. Opt. Eng. 2011, 8066, 80660N, doi:10.1171/12.887500.

3. Abdurahmanov, E.; Daminov, G.; Sultanov, M.; Tillaev, S. Maintenance of selectivity thermacathalytical sensor control of components of ex-haust gases. Ecol. Syst. Devices 2008, 5, 30-32.

4. Karpova, E.; Mironov, S.; Suchkov, A.; Karelin, A.; Karpov, E.E.; Karpov, E.F. Increase of catalytic sensors stability. Sens. Actuators B Chem. 2014, 197, 358-363, doi:10.1016/j.snb.2014.03.016.

(C) 2017 by the authors. Licensee MDPI, Basel, Switzerland. This article is an open access article distributed under the terms and conditions of the Creative Commons Attribution (CC BY) license (http://creativecommons.org/licenses/by/4.0/). 